\title{
Hubungan Status Ekonomi dengan Keputusan Tidak Menggunakan Gigi Tiruan di Kelurahan Teling Atas
}

\author{
Kusuma Dewi \\ Krista V. Siagian \\ Vonny N. S. Wowor \\ Program Studi Pendidikan Dokter Gigi Fakultas Kedokteran \\ Univeristas Sam Ratulangi Manado \\ Email: dewiero21@gmail.com
}

\begin{abstract}
High rate of tooth loss in Indonesia indicates that oral health is still a problem. Ideally, people who lose teeth will replace the missing teeth with using denture but not in the reality. Many factors could influence the background of people's decisions, including cost. The relatively expensive cost of denture becomes an obstacle if the community is faced to various other needs that must be fulfilled including basic needs. Economic status will take a great deal in making decision. This study was aimed to assess whether there was a relationship between economic status and the decision of not using denture among people at Kelurahan Teling Atas. This was a descriptive analytical study with a cross sectional design. Population consisted of people who had tooth loss but did not replace it with using denture as many as 123 people. Samples were 55 people obtained by using purposive sampling method. The instrument in this study was a questionnaire. The results showed that $38.2 \%$ of respondents had low economic status, $25.4 \%$ had medium economic status, and $36.4 \%$ had high economic status. Respondents with positive decisions of not using dentures related to the cost were 62.09\%. The Pearson chi-square showed a p-value of 0.003. In conclusion, there was a significant relationship between economic status and decision to not using denture.
\end{abstract}

Keywords: economic status, decision of using denture

\begin{abstract}
Abstrak: Tingginya angka kehilangan gigi di Indonesia menandakan bahwa kesehatan gigi dan mulut masih menjadi masalah. Idealnya masyarakat yang kehilangan gigi akan menggantikan gigi asli yang hilang dengan gigi tiruan, namun kenyataannya belum demikian. Banyak faktor yang melatarbelakangi keputusan masyarakat, antara lain faktor biaya. Biaya perawatan gigi tiruan yang relatif mahal menjadi kendala jika masyarakat diperhadapkan dengan berbagai alternatif kebutuhan yang harus dipenuhi, termasuk kebutuhan pokok. Status ekonomi dalam hal ini adalah daya beli masyarakat akan turut berperan dalam pengambilan keputusan dimaksud. Penelitian ini bertujuan untuk mengetahui adanya hubungan antara status ekonomi dengan keputusan tidak menggunakan gigi tiruan pada masyarakat di Kelurahan Teling Atas. Jenis penelitian ialah deskriptif analitik dengan desain potong lintang. Populasi penelitian ini yaitu individu yang telah kehilangan gigi namun tidak menggantikannya dengan gigi tiruan, berjumlah 123 orang. Jumlah sampel sebesar 55 orang, diambil dengan metode purposive sampling. Instrumen penelitian menggunakan kuesioner. Hasil penelitian mendapatkan responden dengan status ekonomi rendah sebesar 38,2\%, status ekonomi menengah sebesar $25,4 \%$, dan status ekonomi tinggi sebesar $36,4 \%$. Responden dengan keputusan positif tidak menggunakan gigi tiruan terkait biaya sebesar 62,09\%. Hasil uji statistik menggunakan Pearson chi square mendapatkan nilai $\mathrm{p}=0,003$. Simpulan peneleitian ini ialah terdapat hubungan antara status ekonomi dengan keputusan tidak menggunakan gigi tiruan.
\end{abstract}

Kata kunci: status ekonomi, keputusan menggunakan gigi tiruan 
Kesehatan gigi mulut merupakan bagian dari kesehatan tubuh yang tidak dapat dipisahkan satu dengan yang lainnya. Tubuh dikatakan sehat secara utuh jika fisik, mental, sosial, dan juga rohani sehat. ${ }^{1}$ Apabila ada salah satu bagian tubuh yang bermasalah, maka belum bisa dikatakan sehat secara utuh. Gigi-geligi adalah bagian dari sistem pengunyahan, kehilangan gigi dapat mengakibatkan gangguan pada fungsi pengunyahan, fungsi temporomandibular joint (TMJ), dan psikologis yaitu estetika dan fungsi bicara. Oleh karena itu, gigi asli yang hilang selayaknya diganti dengan gigi tiruan untuk mengembalikan fungsi yang hilang. $^{2}$

Data Riset Kesehatan Dasar (RISKESDAS) tahun 2018 mencatat proporsi masalah gigi dan mulut sebesar 57,6\%, meningkat dari data RISKESDAS 2013 sebesar $25,9 \%$. Salah satu masalah kesehatan gigi mulut, yakni masalah kehilangan gigi. Persentase kehilangan gigi pada usia 35-44 tahun tercatat sebesar $0,4 \%$, dan semakin meningkat seiring bertambahnya usia. Pada usia 65 tahun ke atas mencapai 17,6\%. Di Sulawesi Utara angka ini lebih tinggi daripada angka nasional yaitu sebesar $0,9 \% .^{3}$ Idealnya kehilangan gigi harus dibuatkan penggantinya guna mengantisipasi timbulnya berbagai gangguan berkaitan dengan fungsi yang hilang. Dari kasus kehilangan gigi yang ada, tidak semua menggunakan gigi tiruan. Persentase pengguna gigi tiruan di Sulawesi Utara mencapai $7,1 \%{ }^{4}$

Keputusan untuk mengggunakan gigi tiruan dipengaruhi oleh beberapa faktor. Beberapa faktor yang dapat dihubungkan dengan pemakaian gigi tiruan, antara lain tingkat sosial ekonomi, tingkat pendidikan, dan penghasilan. Seseorang yang berpendidikan dan mempunyai penghasilan cukup akan secara rutin melakukan perawatan gigi dan mulut, termasuk perawatan gigi tiruan. ${ }^{5}$ Perawatan kesehatan gigi mulut merupakan perawatan yang relatif mahal bagi sebagian masyarakat, salah satunya perawatan pembuatan gigi tiruan. Banyak masyarakat yang tidak menggunakan gigi tiruan karena pertimbangan faktor ekonomi, walaupun terdapat banyak alasan lain yang melatarbelakangi keputusan tidak menggunakan gigi tiruan.

Perawatan gigi tiruan merupakan jenis perawatan dengan cara membuatkan alat tiruan untuk menggantikan gigi asli yang hilang serta jaringan pendukung di sekitarnya. ${ }^{6}$ Perawatan ini dikatakan mahal karena perawatan pembuatan gigi tiruan mencakup perawatan klinis dan laboratoris. Mahalnya perawatan ditentukan juga oleh banyaknya gigi yang hilang serta jenis gigi tiruan yang dibuat. Biaya merupakan salah satu hambatan utama untuk memperoleh gigi tiruan. ${ }^{7}$ Bahkan mahalnya biaya perawatan gigi mulut terasa hingga di sebagian besar negara industri, dimana perawatan gigi mulut merupakan perawatan dengan biaya ke empat termahal. ${ }^{8}$

Pada survei awal yang dilakukan di Kelurahan Teling Atas ditemukan banyak masyarakat yang mengalami kehilangan gigi, namun gigi asli yang hilang tidak diganti dengan gigi tiruan. Salah satu alasan yang ditemukan yakni berkaitan dengan faktor ekonomi. Kelurahan Teling Atas merupakan salah satu kelurahan di Kecamatan Wanea dengan populasi penduduk sebesar 13.679. Masyarakat Kelurahan Teling Atas yang sebagian besar bekerja sebagai Aparatur Sipil Negara (ASN) memiliki penghasilan tetap dan dapat bertambah seiring dengan kenaikan pangkat serta pekerja lepasan yang tidak memiliki penghasilan menentu. Berdasarkan latar belakang yang dikemukakan di atas, penulis tertarik melakukan penelitian mengenai hubungan status ekonomi dengan keputusan tidak menggunakan gigi tiruan pada masyarakat Kelurahan Teling Atas.

\section{METODE PENELITIAN}

Penelitian ini dilaksanakan di Kelurahan Teling Atas Kecamatan Wanea Manado pada bulan Mei 2019. Jenis penelitian ialah deskriptif analitik dengan desain potong lintang.

Populasi penelitian ini yaitu masyarakat Kelurahan Teling Atas yang berusia 21-60 tahun sebanyak 123 orang yang telah kehilangan gigi namun tidak menggunakan 
gigi tiruan. Jumlah sampel pada penelitian ini dihitung menggunakan rumus Slovin yaitu sebanyak 55 responden.

Kriteria inklusi dalam penelitian ini yaitu masyarakat Kelurahan Teling Atas yang mengalami kehilangan gigi, namun tidak menggunakan gigi tiruan, bersedia menjadi responden dengan menandatangani informed consent. Kriteria eksklusi yaitu responden yang mengalami hambatan dalam berkomunikasi dan tidak bersikap koorperatif selama pengambilan data.

Pengambilan sampel menggunakan metode purposive sampling, yaitu pengambilan sampel berdasarkan pertimbangan peneliti yakni dengan cara mendatangi rumah-rumah penduduk dan yang memenuhi kriteria inklusi dimasukkan sebagai responden penelitian hingga sebanyak 55 orang terkumpul.

\section{HASIL PENELITIAN}

Kelurahan Teling Atas merupakan salah satu kelurahan di Kecamatan Wanea Kota Manado. Jumlah penduduk di Kelurahan Teling Atas sebanyak 13.679 jiwa, dengan sebaran jenis kelamin lakilaki sebanyak 6.806 orang dan perempuan 6.873 orang.

Pada penelitian ini didapatkan 55 responden, terdiri dari 24 orang laki-laki $(43,6 \%)$ dan 31 orang perempuan $(56,4 \%)$. Responden yang telah menikah berjumlah 29 orang (53\%) dan yang belum menikah berjumlah 26 orang (47\%). Karakteristik responden meliputi jenis kelamin, usia, pendidikan terakhir, anggungan keluarga, dan tingkat pendapatan disajikan dalam bentuk tabel distribusi frekuensi.

Tabel 1 menunjukkan bahwa paling banyak responden berada pada kelompok usia 21-25 tahun, yaitu sebanyak 24 responden $(43,6 \%)$ dan yang paling sedikit berada pada kelompok 56-60 tahun, yaitu sebanyak 3 responden $(5,4 \%)$.

Tabel 2 menunjukkan bahwa tingkat pendidikan terakhir responden yang paling banyak terdapat pada jenjang pendidikan SMA/sederajat, yaitu sebanyak 33 responden $(60 \%)$, diikuti jenjang pendidikan Sarjana sebanyak 17 responden (30\%),
Diploma dan SMP masing-masing sebanyak 2 responden (4\%) dan jumlah responden paling sedikit terdapat pada jenjang pendidikan SD yaitu sebanyak 1 responden $(2 \%)$.

Tabel 1. Distribusi frekuensi responden berdasarkan usia

\begin{tabular}{ccc}
\hline Usia (tahun) & $\mathbf{n}$ & $\boldsymbol{\%}$ \\
\hline$\leq 25$ & 24 & 43,6 \\
$26-35$ & 6 & 10,9 \\
$36-45$ & 14 & 25,4 \\
$46-55$ & 8 & 14,5 \\
$\geq 56$ & 3 & 5,4 \\
Total & 55 & 100 \\
\hline
\end{tabular}

Tabel 2. Distribusi frekuensi responden berdasarkan pendidikan terakhir

\begin{tabular}{ccc}
\hline $\begin{array}{c}\text { Pendidikan } \\
\text { Terakhir }\end{array}$ & n & \% \\
\hline SD & 1 & 2 \\
SMP & 2 & 4 \\
SMA/Sederajat & 33 & 60 \\
Diploma & 2 & 4 \\
Sarjana & 17 & 30 \\
Total & 55 & 100 \\
\hline
\end{tabular}

Tabel 3 menunjukkan bahwa sebanyak 21 responden $(38,2 \%)$ memiliki pendapatan $\leq$ Rp.3.000.000,00 (tergolong tingkat ekonomi rendah); 14 responden $(25,4 \%)$ memiliki pendapatan berkisar antara $\mathrm{Rp}$. 3.000.000,00-5.000.000,00 (tergolong tingkat ekonomi menengah); dan sebanyak 20 responden $(36,4 \%)$ memiliki pendapatan >Rp. 5.000.000,00 (tingkat ekonomi tinggi).

Tabel 3. Distribusi frekuensi responden berdasarkan status ekonomi

\begin{tabular}{cccc}
\hline $\begin{array}{c}\text { Tingkat } \\
\text { Pendapatan } \\
(\mathbf{R p})\end{array}$ & $\begin{array}{c}\text { Status } \\
\text { Ekonomi }\end{array}$ & $\mathbf{n}$ & $\mathbf{\%}$ \\
\hline$>5.000 .000,00$ & Tinggi & 20 & 36,4 \\
$3.000 .000,00-$ & Menengah & 14 & 5,4 \\
$5.000 .0000,00$ & & & \\
$\leq 3.000 .000,00$ & Rendah & 21 & 38,2 \\
Total & & 55 & 100 \\
\hline
\end{tabular}


Tabel 4 menunjukkan bahwa berdasarkan tanggungan keluarga, paling banyak responden tidak memiliki tanggungan keluarga, yakni sebanyak 20 responden $(36,4 \%)$, dan yang paling sedikit ialah memiliki tanggungan 5 orang, sebanyak 1 responden (2\%). Responden berstatus ekonomi rendah dan tidak memiliki tanggungan yang terbanyak yaitu 8 orang (14,5\%). Responden berstatus ekonomi menengah dan tidak memiliki tanggungan yang terbanyak yaitu 6 orang $(10,9 \%)$. Responden berstatus ekonomi tinggi dan tidak memiliki tanggungan yang terbanyak yaitu 6 orang $(10,9 \%)$.

Tabel 5 memperlihatkan hasil pengambilan keputusan menggunakan gigi tiruan, yaitu sebesar 62,09\% memiliki keputusan positif terkait dengan alasan yang menda- sari keputusan yang diambil.

Tabel 6 menunjukkan bahwa seluruh responden dengan status ekonomi rendah memiliki keputusan positif untuk tidak menggunakan gigi tiruan yaitu sebanyak 21 orang $(38,2 \%)$. Pada responden dengan status ekonomi menengah, sebanyak 10 orang $(18,2 \%)$ memiliki keputusan positif dan sebanyak 4 orang $(7,3 \%)$ memiliki keputusan negatif. Pada responden dengan status ekonomi tinggi, jumlah responden yang memiliki keputusan positif dan negatif hampir sama banyak (11 vs 9 orang).

Hasil analisis dengan menggunakan uji statistik chi-square di peroleh nilai 0,003 (< 0,05), yang menunjukkan bahwa terdapat hubungan bermakna antara status ekonomi dengan keputusan tidak menggunakan gigi tiruan.

Tabel 4. Distribusi frekuensi status ekonomi berdasarkan tanggungan keluarga

\begin{tabular}{ccccccccc}
\hline $\begin{array}{c}\text { Tanggungan } \\
\text { keluarga }\end{array}$ & \multicolumn{2}{c}{ Tinggi } & \multicolumn{2}{c}{ Menengah } & \multicolumn{2}{c}{ Rendah } & \multicolumn{2}{c}{ Jumlah } \\
\hline & $\mathrm{n}$ & $\%$ & $\mathrm{n}$ & $\%$ & $\mathrm{n}$ & $\%$ & $\mathrm{n}$ & $\%$ \\
0 & 6 & 10,9 & 6 & 10,9 & 8 & 14,5 & 20 & 36,4 \\
1 & 5 & 9,1 & 2 & 3,6 & 2 & 3,6 & 9 & 16,4 \\
2 & 5 & 9,1 & 5 & 9,1 & 6 & 10,9 & 16 & 29,1 \\
3 & 3 & 5,5 & 0 & 0 & 4 & 7,3 & 7 & 12,7 \\
4 & 0 & 0 & 1 & 1,8 & 1 & 1,8 & 2 & 3,6 \\
5 & 1 & 1,8 & 0 & 0 & 0 & 0 & 1 & 1,8 \\
Total & 20 & 36,4 & 14 & 25,4 & 21 & 38,2 & 55 & 100 \\
\hline
\end{tabular}

Tabel 5. Distribusi skor pengukuran keputusan responden tidak menggunakan gigi tiruan

\begin{tabular}{|c|c|c|c|c|c|c|c|}
\hline \multirow[t]{2}{*}{ No } & \multirow[t]{2}{*}{ Pernyataan } & \multicolumn{5}{|c|}{ Alternatif jawaban } & \multirow[t]{2}{*}{ Skor } \\
\hline & & STS & TS & BS & S & SS & \\
\hline 1 & Biaya pembuatan gigi tiruan mahal & 0 & 2 & 11 & 27 & 15 & 220 \\
\hline 2 & $\begin{array}{l}\text { Penghasilan tidak mencukupi untuk mem- } \\
\text { biayai pengeluaran lain di luar kebutuhan } \\
\text { pokok }\end{array}$ & 0 & 10 & 24 & 20 & 1 & 177 \\
\hline 3 & $\begin{array}{l}\text { Tidak ada biaya untuk berobat ke dokter } \\
\text { gigi }\end{array}$ & 11 & 18 & 21 & 5 & 0 & 130 \\
\hline 4 & Banyak kebutuhan lain yang harus dibiayai & 0 & 3 & 9 & 29 & 14 & 219 \\
\hline 5 & $\begin{array}{l}\text { Adanya biaya lain yang harus dibayar } \\
\text { selain biaya pembuatan gigi tiruan } \\
\text { Total }\end{array}$ & 2 & 5 & 10 & 25 & 13 & 212 \\
\hline
\end{tabular}




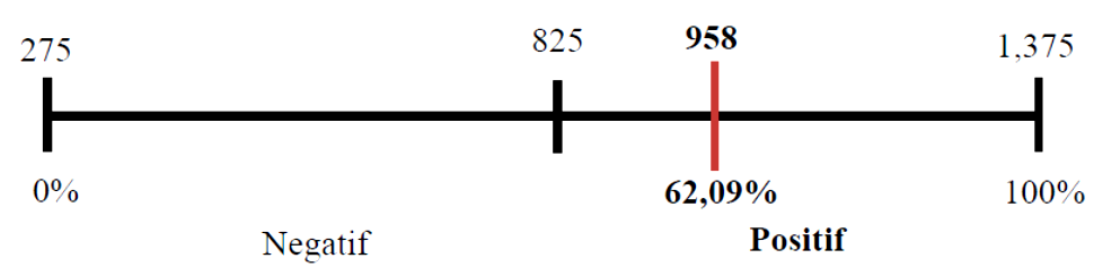

Tabel 6. Tabulasi silang status ekonomi dengan keputusan responden tidak menggunakan gigi tiruan

\begin{tabular}{|c|c|c|c|c|c|c|c|}
\hline \multirow{2}{*}{$\begin{array}{l}\text { Status } \\
\text { ekonomi }\end{array}$} & \multicolumn{4}{|c|}{ Keputusan } & \multicolumn{2}{|c|}{ Jumlah } & \multirow[t]{2}{*}{ Nilai $p$} \\
\hline & \multicolumn{2}{|c|}{ Positif } & \multicolumn{2}{|c|}{ Negatif } & & & \\
\hline & $\mathrm{n}$ & $\%$ & $\mathrm{n}$ & $\%$ & $\mathrm{n}$ & $\%$ & \\
\hline Rendah & 21 & 38,2 & 0 & 0 & 21 & 8,2 & \\
\hline Menengah & 10 & 18,2 & 4 & 7,3 & 14 & 5,4 & 0,003 \\
\hline Tinggi & 11 & 20 & 9 & 16,4 & 20 & 6,4 & \\
\hline Total & 42 & 76,4 & 13 & 23,6 & 55 & 100 & \\
\hline
\end{tabular}

\section{BAHASAN}

Pada penelitian ini dinilai hubungan status ekonomi dengan keputusan tidak menggunakan gigi tiruan. Status ekonomi diukur dari kondisi yang menggambarkan kemampuan ekonomi responden untuk membiayai perawatan penggunaan gigi tiruan, serta dari pendapatan bulanan responden. Status ekonomi yang stabil menjadi salah satu pendorong bagi responden untuk melakukan perawatan gigi tiruan ketika responden membutuhkan. Bila biaya perawatan terjangkau dan sesuai dengan pendapatan yang didapatkan, maka hal itu menjadi salah satu faktor yang mendorong yang bersangkutan untuk melakukan perawatan gigi tiruan.

Hasil penelitian ini memperlihatkan $38,2 \%$ responden berpenghasilan sebanyak $\leq$ Rp. 3.000.000,00 per bulan atau tergolong ekonomi rendah. Angka ini sedikit berimbang dengan responden yang berekonomi tinggi, yakni sebesar 36,4\% (Tabel 3). Status ekonomi antara lain memberikan gambaran daya beli masyarakat, yakni kemampuan masyarakat sebagai konsumen untuk membeli barang atau jasa yang dibutuhkan. Makin tinggi pendapatan seseorang, maka makin tinggi pula daya belinya. ${ }^{9}$ Pendapatan masyarakat dibutuhkan untuk memenuhi kebutuhan primer, sekunder, maupun tersier. Kebutuhan utama manusia yakni sandang atau berupa pakaian, pangan terkait kebutuhan akan makanan, dan papan berupa kebutuhan akan rumah atau tempat hunian. Kebutuhan primer merupakan kebutuhan utama yang menjadi prioritas untuk dipenuhi. Namun, seiring dengan kemajuan dan perkembangan zaman, kini kebutuhan akan kesehatan serta pendidikan masuk menjadi kebutuhan primer atau kebutuhan pokok manusia dan kebutuhan akan perawatan gigi mulut merupakan salah satu kebutuhan kesehatan.

Dalam kehidupan sehari-hari tidak semua individu yang kehilangan gigi akan menggantikan gigi aslinya yang hilang dengan gigi tiruan. Berbagai faktor dapat menjadi alasan untuk mengambil keputusan tidak menggunakan gigi tiruan.

Hasil penelitian mendapatkan bahwa mengenai keputusan tidak menggunakan gigi tiruan oleh responden yang tidak menggunakan gigi tiruan, terlihat bahwa sebagian besar keputusan responden terkait alasan biaya atau alasan ekonomi (Tabel 6). Keputusan responden tidak menggunakan gigi tiruan antara lain didasari oleh karena biaya pembuatan gigi tiruan yang mahal. Penghasilan yang ada tidak mencukupi untuk pembiayaan lain di luar biaya 
kebutuhan pokok, banyaknya kebutuhan yang harus dibiayai, dan adanya biaya lain yang harus dibayarkan. Hasil pengukuran skor keputusan responden tidak menggunakan gigi tiruan, mendapatkan 62,09\% memiliki keputusan positif terkait dengan alasan yang mendasari keputusan yang diambil. Respon positif menggambarkan pengambilan keputusan tidak menggunakan gigi tiruan ada keterkaitannya dengan faktor biaya atau daya beli. Hasil penelitian ini didukung oleh pendapat Tulangouw et $\mathrm{al}^{10}$ yang menyatakan bahwa, status ekonomi merupakan salah satu faktor yang memengaruhi status kesehatan. Individu dengan status ekonomi yang memadai lebih memungkinkan untuk dapat memenuhi berbagai kebutuhan pokok hidupnya termasuk mendapatkan tempat pelayanan kesehatan yang diinginkan dibandingkan dengan kelompok sosial ekonomi rendah.

Keputusan tidak menggunakan gigi tiruan selain menyangkut biaya, juga melibatkan beberapa faktor, di antaranya ialah usia, dan tanggungan keluarga responden. Tabel 2 memperlihatkan responden berusia $\leq 25$ tahun merupakan responden dengan jumlah terbanyak $(43,6 \%)$. Usia ini merupakan kelompok usia remaja akhir. ${ }^{11}$ Majunya teknologi komunikasi yang ditandai dengan begitu maraknya alat komunikasi canggih yang dipasarkan, seperti smartphone dengan berbagai fitur yang menarik sepertinya menjadi idaman kaum muda. Dunia internet yang begitu mudahnya diakses dari smartphone menjadikan alat komunikasi ini begitu digandrungi oleh para remaja bahkan anak-anak hingga orang dewasa. Handphone bukan lagi sekedar sebagai alat komunikasi tapi sudah berkembang menjadi simbol status, bahkan jadi kebutuhan utama para remaja. Studi yang dilakukan oleh lembaga PBB untuk anak-anak, UNICEF, bersama para mitra termasuk Kementerian Komunikasi dan Informatika serta Universitas Harvard, AS untuk menelusuri aktivitas online anak hingga remaja menunjukkan bahwa $79,5 \%$ merupakan pengguna internet. ${ }^{12}$

Data Tabel 6 menarik untuk dicermati karena yang memiliki keputusan positif tidak menggunakan gigi tiruan bukan hanya berstatus ekonomi rendah $(38,2 \%)$ namun juga yang berstatus ekonomi menengah $(18,2 \%)$ dan tinggi (20\%). Tuntutan gaya hidup merupakan faktor yang sangat berperan pada usia remaja akhir ketika harus menentukan pengeluaran uang untuk berbagai kebutuhan, termasuk kebutuhan akan kesehatan. Sangat besar kemungkinan ketika mereka dihadapkan dengan kebutuhan untuk membiayai kesehatan, dana yang tersedia sudah tidak lagi memadai karena masih ada kebutuhan pokok yang harus dipenuhi. Demikian halnya dengan responden dari kelompok usia 36-45 tahun yang merupakan kelompok usia dewasa. ${ }^{11}$ Dunia internet yang begitu mudahnya diakses sekarang ini lewat smartphone di samping membuat dunia informasi dan pengetahuan yang begitu terbuka, namun juga secara tidak langsung menggiring masyarakat menjadi masyarakat consumeris. Berbagai penawaran terlebih khusus kebutuhan sekunder begitu menarik dipasarkan di internet. Teknik penjualan yang begitu inovatif dan memanjakan konsumen membuat banyak masyarakat secara tidak sadar menjadi konsumeris. Tidak mengherankan jika respoden dengan status ekonomi tinggi bisa memiliki keputusan positif tidak menggunakan gigi tiruan. Apalagi jika kehilangan gigi relatif tidak begitu memengaruhi fungsi kunyah atau estetik.

Di samping itu jumlah tanggungan anak juga memengaruhi besarnya pengeluaran (Tabel 4). Responden dengan status ekonomi yang sama, baik pada status ekonomi tinggi ataupun pada status ekonomi menengah; namun berbeda dalam jumlah tanggungan keluarga, bisa saja memiliki keputusan yang berbeda ketika harus memutuskan untuk mengeluarkan biaya ekstra di luar biaya untuk kebutuhan pokok. Responden dengan jumlah tanggungan keluarga lebih besar ketika diperhadapkan dengan keputusan untuk menggunakan atau tidak menggunakan gigi tiruan ketika mengalami kehilangan gigi, akan membuat keputusan yang sama dengan responden yang berstatus ekonomi rendah. Hal ini terjadi oleh karena biaya 
yang dikeluarkan untuk membiayai kebutuhan keluarga dengan tanggungan anggota keluarga yang banyak akan lebih besar dibandingkan biaya yang dikeluarkan oleh keluarga dengan status ekonomi yang sama namun jumlah tanggungan lebih kecil atau bahkan sama sekali tidak ada tanggungan. Hasil penelitian yang dilakukan oleh Purwanto $\mathrm{A}$ et $\mathrm{al}^{13}$ menyatakan bahwa jumlah tanggungan keluarga akan sangat berdampak besar pada tingkat kesejahteraan keluarga ketika tidak diimbangi dengan jumlah pendapatan yang sesuai. Dengan demikian tidaklah mengherankan walaupun ditemukan responden berstatus ekonomi menengah hingga tinggi mendominasi atau lebih besar jumlahnya dari responden yang berstatus ekonomi rendah (21\%) seperti yang diperlihat dalam Tabel 4 , namun hasil yang ada dalam (Tabel 5) menunjukkan $62,09 \%$ memiliki keputusan positif. Jelas bahwa faktor biaya sangat memegang berperan penting dalam pengambilan keputusan responden, dalam hal ini daya beli responden terkait erat dengan status ekonomi. Hasil penelitian ini didukung oleh pendapat Haryani et $\mathrm{al}^{14}$ yang menyatakan bahwa status ekonomi merupakan kemampuan finansial untuk memenuhi segala kebutuhan hidup dan bisa digunakan untuk membiayai semua program pengobatan dan perawatan.

Hasil analisis hubungan status ekonomi dengan keputusan tidak menggunakan gigi tiruan berdasarkan uji statistik dengan menggunakan korelasi Pearson chisquare pada Tabel 6 mendapatkan nilai signi-fikansi atau Asymp.Sig. (2 sided) $=$ 0,003 , yaitu $<0,05$. Hasil ini menunjukkan bahwa terdapat hubungan bermakna antara status ekonomi dengan keputusan tidak menggu-nakan gigi tiruan pada masyarakat di Kelurahan Teling Atas. Hal ini selaras dengan penelitian yang dilakukan oleh Pessoa et al $^{15}$ yang menunjukkan bahwa terdapat hubungan bermakna antara status ekonomi dengan kebutuhan pemakaian gigi tiruan. Faktor biaya yang terkait erat dengan status ekonomi merupakan alasan yang mendasari keputusan untuk tidak menggunakan gigi tiruan. Kondisi ekonomi seseorang menjadi penunjang utama untuk memenuhi kebutuhan perawatan gigi tiruan, sehingga dapat dikatakan pembiayaan perawatan gigi tiruan erat hubungannya dengan status ekonomi seseorang. ${ }^{16}$ Demikian pula Rahman et $\mathrm{al}^{17}$ dalam penelitiannya menyatakan faktor yang paling menghambat permintaan perawatan pembuatan gigi tiruan ialah dikarenakan biaya pembuatan gigi tiruan yang mahal.

\section{SIMPULAN}

Berdasarkan hasil penelitian ini dapat disimpulkan bahwa terdapat hubungan bermakna antara status ekonomi dengan keputusan tidak menggunakan gigi tiruan di Kelurahan Teling Atas.

Disarankan agar pemerintah meningkatkan kesejahteraan masyarakat melalui peningkatan pendidikan dan penyediaan lapangan kerja, sehingga mampu meningkatkan status ekonomi masyarakat dan meningkatkan daya beli masyarakat. Bagi masyarakat Kelurahan Teling Atas disarankan agar lebih memerhatikan dan mendahulukan pemenuhan kebutuhan kesehatan termasuk kesehatan gigi mulut di samping pemenuhan kebutuhan pokok seperti sandang, pangan, papan, serta kebutuhan pendidikan.

\section{DAFTAR PUSTAKA}

1. Chandra B. Ilmu kedokteran pencegahan komunitas. Jakarta: EGC. 2006.

2. Maluwere VO, Mariati NW, Wicaksono DA. Gambarana kebersihan mulut pada pemakai gigi tiruan sebagian lepasan di Kecamatan Batu Kota Malalayang. eGiGi. 2015;3(1):197-202.

3. Departemen Kesehatan Republik Indonesia. Laporan Riset Kesehatan Dasar Nasional 2007 dan 2013. Jakarta: Badan Penelitian dan Pengembangan Kesehatan, 2008; p. 146-76.

4. Departemen Kesehatan Republik Indonesia. Laporan Riset Kesehatan Dasar Nasional 2007. Jakarta: Badan Penelitian dan Pengembangan Kesehatan, 2008.

5. Siagian KV. Kehilangan sebagian gigi pada rongga mulut. e-CliniC. 2016;4(1).

6. Pongsibidang H, Wowor VNS, Supit A. 
Alasan masyarakat Kelurahan Sario Tumpaan tidak menggunakan gigi tiruan. e-GiGi. 2013;1(2).

7. Mursyid P. Faktor-faktor yang mempengaruhi pasien dalam pemilihan jenis gigi tiruan di Pulau Kodingaren [Skripsi]. Makassar: Fakultas Kedokteran Gigi Universitas Hassanudin; 2011.

8. Sheiham A. Strategies for oral health care. Euro Observer. 2002;7:1-4.

9. Pawenag S. Modul perkuliahan lingkungan ekonomi bisnis. Program Pascasarjana. Surakarta: UNIBA, 2016.

10. Tulangow JT. Mariati NW, Mintjelungan C. Gambaran status karies murid Sekolah Dasar Negeri 48 Manado berdasarkan status sosial ekonomi orang tua. e-GiGi. 2013;1(2):85-93.

11. Departemen Kesehatan Republik Indonesia. Pembagian kategori usia. [situs resmi] 2009. Available from: http:// depkes. go.id

12. Panji A, Wahyudi R. Hasil survei pemakaian internet remaja Indonesia [artikel berita] 2014; [cited 2019 Sept 9]. Available from: http://www.kompas. com/tekno/read/2014/02/19/1623250/H asil.Survei.Pemakaian.Internet.Remaja.
Indonesia

13. Purwanto A, Taftazani BM. Pengaruh jumlah tanggungan keluarga pekerja K3L. Jurnal Pekerjaan Sosial. 2018: 1(2):33-43.

14. Haryani W, Purwati DE, Satrianingsih S. Hubungan antar tingkat pendidikan dan status ekonomi dengan kepatuhan perawatan gigi tiruan lepasan. Majalah Kedokteran Gigi Indonesia. 2017;3(3): 160-6.

15. De Veiga Pessoa DM, Roncalli AG, de Lima KC. Economic and sociodemographic inequalities in complete denture need among older Brazilian adults: a cross-sectional populationbased study. BMC Oral Health. 2017; 17(5):1-8.

16. Harini S. Pengaruh tingkat pendidikan dan sosial ekonomi dengan kebutuhan pemakaian gigi tiruan sebagian lepasan [Skripsi]. Yogyakarta: Universitas Gadjah Mada; 2005.

17. Rahman F, Saputera D, Adhani R. Faktor yang mempengaruhi permintaan gigi tiruan pada lansia (tinjauan terhadap biaya perawatan, kecemasan, dan sarana). Stomagtomatic. 2016;13(1);10. 